\title{
Notas sobre el problema autor y su función
}

\section{Cristián Santibáñez Yáñez}

Universidad de H ouston, USA

E-mail: Christian.Santibanez@mail.uh.edu

\section{Resumen}

En este artículo se recuperan algunas de las reflexiones utilizadas en la teoría literaria y los estudios culturales que, sacudidos por el "caso Sokal", intentan explicar la función de la categoría "autor". En particular, sirven de apoyo para sostener que "autor" es una categoría colectiva, un tipo deideologema, un mecanismo ecoico, argumentos expuestos por Barthes, Foucault, Bourdieu, Jameson y Vattimo, entre otros. Se añaden también notas historiográficas de la evolución del concepto "autor" de la mano de los estudios de Burke, quenos ayudan a apreciar que el registro "autor" fue una jugada comercial, durantela etapa tardía dela Edad M edia y el comienzo del Renacimiento, para certificar como propiedad individual la distribución del conocimiento social.

Palabras claves: Autor, individualidad, discurso, ideologema, subjetividad, voz colectiva.

\section{Abstract}

In this paper I will apply certain arguments of literary theory and cultural studies, including those attacked in the "Sokal case", in order to explain the function of the category "author". In particular, I will synthesize reflections of Barthes, Foucault, Bourdieu, Jameson and Vattimo, among others, to claim that "author" is a collective category and an ideologeme. I will add historical notes about the evolution of the concept of "author" through Burke's worksto demonstratethat the development of "author" is partially dueto economic or commercial reasons: during the late stages of the M edieval Age and Renaissance, there was a move to register "social knowledge" as individual property.

Keywords: Author, individuality, discourse, ideologeme, subjectivity, collective voice. Recibido: 15-05-2003. Aceptado: 28-10-2003.

1. CREAD OR, dador, causante, fundador, inventor, instigador, responsable, Luente, fiador, emisor..., palabras todas que en latín estaban asociadas a la de autor y que en el español actual, en una lectura natural, desimplicada, siguen 
rigiendo sus derroteros semánticos en contextos varios. En efecto, si seguimos la relación entre los conceptos creador-autor, toparíamos con la común acepción que atribuye al creador la autoría de un artefacto ${ }^{1 ;}$, si seguimos el vínculo, estrechísimo, entre inventor-autor, por ejemplo, llegaríamos a la noción de autor como propietario de una realización; más aún, desde la relación autor-emisor, nos encontraríamos con la recurrente definición de emisor como autor de las modalidades de un mensaje en una comunicación.

Las asociaciones del concepto autor no terminan aquí, por cierto. En realidad, es una palabra carente de neutralidad, sofocada por sus significaciones, pues sus connotaciones corrientes la unen con tópicos como el de autonomía, iniciativa, invención, creatividad, autoridad, y éstos a su vez nos recuerdan las relaciones entre autor y conceptos tales como individuo, sujeto y persona, las que han sido abordadas por la sociología, en el caso de su vinculación con individuo ${ }^{2}$, por la epistemología, en relación con la noción de sujeto33, y por el derecho en el caso de person $a^{4}$. En estas y otras vinculaciones semánticas persiste un sentido elemental de establecer al autor como unidad.

N o obstante, estas entradas al concepto autor ya no monopolizan la reflexión. Existe un intento crítico contemporáne ${ }^{5}$, con cierta diseminación ya en los ambientes cotidianos, que enfatiza lo inapropiado que es vincular a la noción de autor las propiedades de autonomía en la acción, originalidad en lo creado, individualidad en la producción. En este texto van algunas notas sobre este punto de inflexión, de este movimiento al origen dialógico, en particular lo relacionado con la producción literaria, en sentido amplio.

${ }^{1}$ Uno de los significados básicos de la noción de artefacto es aquel que lo concibe como un hecho artístico o técnico - artificial, no dado- creado a partir de una intervención humana con algún tipo deintención o concepto previo nacido de una experiencia común. Para una perspectiva general sobre el papel de los artefactos en la evolución social, ver Ingold (1991).

${ }^{2}$ Casi sin excepción los teóricos en sociología tratan la relación individuo-sociedad. En la sociología alemana contemporánea, vinculada a Luhmann (1993), se encuentra una versión sui generis sobre esta relación, que considera que la constitución del individuo, o sistema psíquico, está en función de la comunicación social: el individuo emerge en el entorno de la comunicación.

${ }^{3}$ La bibliografía sobre este aspecto es abundante, desde filósofos clásicos como D escartes, H umeo N ietzsche, hasta los contemporáneosFoucault (1987), I báñez (1991), Toulmin (1972), Vattimo (1992), entre muchos.

${ }^{4}$ Las constituciones políticas de los estados nacionales, sin duda a partir de las reflexiones del derecho filosófico, tratan este aspecto; ver Pendás (1988).

${ }^{5}$ En lo que sigue, se exponen algunas reflexiones, sobre todo, provenientes de críticos franceses. 0 tro objetivo de estas notas, entonces, es recuperar ciertas propuestas de algunos teóricos sacudidos por Sokal y Bricmont (1999), ya que en general se coincide con estos últimos en que en los primeros hubo un abuso de conceptos y teorías surgidas en la física, la matemática o la química. 
2. $Y$ es un movimiento hacia el origen ya que, en realidad, asistimos a una vuelta, a un genuino eterno retorno en la comprensión social, en este caso, de la función autor, dado que lo que es hoy una preocupación consciente, en el ámbito académico, por trazar las resonancias del carácter construido de la función autor, ha sido en otras épocas una práctica cotidiana, una manifestación comunitaria.

En la época antigua el autor era, en tanto figura protagónica, sólo un vehículo del colectivo ya que formaba parte de un evento total, era una investidura otorgada a al gunos desde la base social, como referente de un universo de significados que actuaba como articulador, como en lace con las divinidades, los vientos, los espíritus, los placeres o los sufrimientos, y no era una fuente individual, auto-producida, existía como punta de fuga de desplazamiento de lo personal hacia lo impersonal ${ }^{6}$, y los únicos que poséan esa individualidad, declarada posible y necesaria posteriormente en una de las versiones de la filosofía moderna, eran los emperadores, religiosos, ancianos o mediadores.

Pero los juegos con las palabras, la creatividad en torno a la disposición de los discursos, la organización de interpretaciones ocurrentes, el atrevimiento con nuevos vocablos, el uso demetáforas sobresalientes, sobretodo en el ámbito científico, y, en particular, la utilización de la imprenta y sus tecnologías asociadas ${ }^{7}$, junto al ensanchamiento del mundo y la concomitante carrera por otorgarse la primicia del descubrimiento, hizo del autor una mayúscula, una autoridad prominente, un trabajo continuo en torno al individualismo. Su momento culminante es la modernidad de $D$ escartes, de aparente racionalidad y aparente filón matemático ${ }^{8}$ que, a pesar de que ya tenía en el trabajo de algunos humanistas del Renacimiento algunos antecedentes ${ }^{9}$, remató con la especificación de las relaciones autor-literatura-ciencia-arte, sumándose a las ya concretas vinculaciones entre explorador-mundo-novedad, reformador-religión, comercianteeconomía, colono-lugar.

\footnotetext{
${ }^{6}$ Sobre la función de los mediadores en la práctica de la magia o la religión en la antigüe dad, es un clásico el texto de Frazer (1998).

O ng (1997) ha expuesto con claridad el papel queha cumplido la tecnología de la palabra escrita y sus mecanismos de difusión, como la imprenta, en el cambio evolutivo humano, acelerando algunas disposiciones, como el individualismo, o disminuyendo otras, como el protagonismo de la memoria.

${ }^{8}$ Para una descripción del ambiente al que responde la filosofía de D escartes y su pretendida racionalidad, ver la discusión de Toulmin (2001).

${ }_{9}^{9}$ Para ver en detalle el papel de ciertos humanistas del Renacimiento temprano italiano y su propagación en el resto deEuropa, ver Burke $(2002,1998,1996)$, Cohen \& Cohen (1993), Cox (1992), M arías (1989), Weiss (1969).
} 
Frente a esta noción de autor, urdida lentamente pero fraguada filosóficamente a partir del siglo XV, quizás como reacción intelectual a una situación material y comercial ${ }^{10}$, algunos filósofos, literatos, lingüistas y analistas sociales del siglo XX reaccionan con cierta vehemencia, intentando construir una idea de autor que esté en una genuina práctica dialógica con el pasado, que incluya, con mayor propiedad, el papel específico que le cabe en el funcionamiento social del conocimiento y su distribución. Sin duda, esta reacción es una apuesta por la superación del dogmatismo, un acto de alto riesgo de disolución del sujeto sobredimensionado, del autor autocomplacido.

3. En particular, Barthes (1981) declara, definitivamente, la muerte del autor, como N ietzsche declarara la muerte de Dios. Barthes declara esta muerte porque, con sus análisis, desvanece la autonomía del escritor y la consistencia de su sentido unívoco. La escritura es un juego discursivo en que el autor, en tanto supuesto uno, es un hacerse en el acto, en el que la experiencia textual de esa función autor desliza al texto y a ese uno que se escribe, donde la idea original, si es que existió, cede terreno a lo intertextual, al horizonte de expectativas del trazo formal del soporte, en red, en tejido. El lenguaje, vehículo del autor, es habla en deriva estructural, como sostiene Barthes (1981) categóricamente:

${ }^{10}$ Algunos antecedentes importantes para entender el surgimiento del autor a partir del Renacimiento son, según Burke(2002), el reconocimiento social depagar por el conocimiento que posee el maestro y evitar las continuas disputas por acusaciones de plagio; el resultado de esto último, evidentemente, fueel comienzo del reconocimiento del derecho de propiedad y la venta del conocimiento, lo cual convirtió a éste en mercancía. Al respecto son elocuentes los siguientes comentarios de Burke (2002):

Durante la Edad M edia, la acción de "compilar" - o recopilar- se convirtió en algo respetable, lo que indicaría que el sentido de propiedad intelectual perdía nitidez. Lo cierto es que durante el siglo XIII el argumento legal tradicional según el cual el conocimiento era "un don de Dios que no puede venderse" fue puesto en tela dejuicio por el nuevo principio según el cual los profesores merecían recibir una paga por su trabajo... D urante el Renacimiento, las disputas sobre los plagios se hicieron cada vez más frecuentes, a pesar de (o debido a) la dificultad de definir la propiedad intelectual. Los humanistas del Renacimiento se acusaban regularmente unos a otros de "robo", aunquetodos afirmaban practicar simplemente una forma de "imitación" creativa... Escritores eimpresores se disputaron entre sí los derechos de propiedad sobre el texto. Tales disputas habría que relacionarlas con el "individualismo", la emulación y la autoconciencia de que habló Jacob Burckhardt en su famoso libro La cultura del Renaci miento en I talia (1860). Están conectadas con la génesis de la idea de "genio", con los orígenes de la "originalidad", el declive del concepto de "autoridad" y el "nacimiento de autor". Esas disputas revelan, además, cambios en el equilibrio entre monopolio y competencia en el campo del conocimiento... (194-5). 
Habrá pues que aceptar el redistribuir los objetos de la ciencia literaria. EI autor, la obra, no son más queel punto de partida de un análisis cuyo horizonte es un lenguaje: no puede haber una ciencia de $D$ ante, de Shakespeare o de Racine, sino únicamente una ciencia del discurso. Esta ciencia tendrá dos grandes territorios, según los signos que habrá de tratar; el primero abarcará los signos inferiores a la frase, tales como las antiguas figuras, los fenómenos de connotación, las "anomalías semánticas", etc., en resumen, todos los rasgos del lenguaje literario en su conjunto; el segundo abarcará los signos superiores a la frase, las partes del discurso de donde pueden inducirse una estructura del relato, del mensaje poético, del texto discursivo, etc. (63).

El autor es una excusa dela escritura, esalguien a quien culpar de posibledesvío, el autor es un rodamiento del lenguaje, no tiene prioridad, ni siquiera posee el estatus suficiente para convertirse en algo menor a la frase.

4. Pasar desde esta crítica formal, de una semiótica general y aun un tanto confusa, a una consideración discursiva y social, desde la filosofía, es una vuelta atribuiblea Foucault (1984), quien retomó, desdeotro ángulo, los aguijones de Barthes contra el trono autorial. Foucault compuso y descompuso el tramado de la formación discursiva del autor, su función legal tradicional, su rol de re presentante del poder y, en un movimiento de sutura epistemológica, retrató el nombredel autor.

Valga decir, por otro lado, que Foucault no asesinó a nadie, muy por el contrario, mostró cómo vivela relación, en complemento y oposición, de persona y autor. Para el efecto, dispone de la noción de autor como función cultural, en la que incluye el imperativo literario de la crítica, en el sentido de que autor es el nombre de la legalidad y, por lo tanto, el blanco del ejercicio crítico. Como función cultural, el autor reúnebajo sí el engranaje dela acusación, defensa y juicio, pero ya no contra la persona, la biografía, sino contra un cierto modo de ser del discurso (60), esto es, contra el nombre de autor.

El nombre autor como entidad, categoría o función general, es una propie dad legal que apoya y es apoyada por los discursos relativos a la libertad, los derechos, las obligaciones, los castigos, etc., es decir, es, como muchos, un siste ma de exclusión e inclusión. Como inclusión, el nombre autor aglutina el saber previo, el saber de la gramática del discurso general, el de la gramática de un subconjunto en el que navegan las referencias permitidas del modo de ser del tipo de discurso del que forma parte (tales como disciplinas, profesiones, corrientes filosóficas, en sentido amplio). Como exclusión, el nombre autor sólo 
permite que ciertas biografías ocupen tal categoría, a partir de usos, reglas y certificados ${ }^{11}$.

Entonces el nombreautor en un discurso no es un individuo que exista aparte de su práctica discursiva, es una función propia del discurso. Esta función está consagrada por la circulación social aceptada, por la necesidad de rúbrica, por la necesidad legal, por la necesidad de distinción, para ordenar, para separar, para dividir, para gobernar. En esta tendencia a la división -social- el nombre propio tiene su sentido y el nombre del autor el suyo, ambos valen lo mismo en sus respectivos circuitos; a partir de este modelamiento de la fracción no es lo mismo un autor filosófico que un autor poeta, ambos se mueven según sus reglas de discurso.

Para mayor claridad, las palabras del autor Foucault (1984):

Se llegará finalmente a la idea de que el nombre de autor no va, como el nombre propio, del interior de un discurso al individuo real y exterior que lo produjo, sino que corre, en cierto modo, en el límite de los textos, los recorta, sigue sus aristas, manifiesta su modo de ser 0 , al menos, lo caracteriza. M anifiesta el acontecimiento deun cierto conjunto del discurso, y se refiere al estatuto de este discurso, en el interior de una sociedad y en el interior de una cultura. El nombre autor no se sitúa en el estado civil de los hombres, ni se sitúa tampoco en la ficción de la obra, se sitúa en la ruptura que instaura un cierto grupo del discurso y su modo de ser singular. Podría decirse, por consiguiente, que en una civilización como la nuestra hay un cierto número de discursos dotados de la función "autor" mientras que otros están desprovistos de ella... Lafunción autor es, entonces, características del modo de existencia, de circulación y de funcionamiento de ciertos discursos en el interior de una sociedad (60-1).

Esos otros discursos desprovistos de la función autor serían aquellos actos de escritura en que el registro de propiedad no es necesario, donde su redactor no debe acomodarse a la forma de ser de una regla de procedimiento. No obstante, es difícil pensar en algún tipo de discurso que no siga alguna regla de uso.

Con todo, y como el propio Foucault resume, la función autor está ligada al sistema jurídico e institucional que encierra, determina, articula el universo de los discursos; no se ejerce de manera uniforme en todas las épocas: no remite pura y simplemente a un individuo real, puede dar lugar a varios ego de manera simultánea, a varias posiciones sujetos, que pueden ocupar diferentes clases de individuos (66).

${ }^{11}$ La obligatoriedad detener certificación parajugar en la ciencia, a través desus disciplinas o profesiones, queda introductoriamente de manifiesto en el trabajo de Lyotard (1993). 
Esta posibilidad deocupar diferentes posiciones-sujetos proviene, también, de la evocación, de la llamada a constituirse como autor por el trazo, por la diferencia, por la necesidad de decir lo no dicho, aquello que quedó aparte; mejor aun, alguien es autor no por lo que intenta decir dada una intuición, creatividad 0 inspiración repentina, autor es autor por lo escondido por otro, por las incongruencias de otro texto, por sus incomplitudes, por sus ignorancias o aciertos deslumbrantes, un autor es alguien porque sigue los hilos de una ruta multiforme, o como sostiene D errida con una metáfora, en rizoma.

5. Pero seguir una ruta, aunque sea en rizoma, es seguir un orden, y en lo que concierne al autor, un orden de escritura, precedido por un orden de lengua, y esta imposición, como toda imposición, tiene la finalidad de conquista y dominación administrativa del territorio - de lo escrito-. En estejuego de apertura de trazo y evocación, por un lado, y de dominación y administración, por otro, el autor es alguien, y nuevamente una función.

Con D errida $(1971,1995)$ esta función de relación de guiño al olvido-vacío o de guiño a la fijación-redundancia, anclada en la lengua, repercute en el trabajo de deconstrucción, pues provoca determinadas formas de ausencia y el autor, simultáneamente, en este sentido, es escrito ${ }^{12}$.

Los ejemplos de este surgimiento de autor lo entregan D eleuze y Guattari (1975) al hablar deliteratura menor, aquella actividad que, en las direcciones posibles que impulsa la diferencia, se juega entre la territorialidad, la desterritorialización y la reterritorialización, relación tripartita de la autoría en lengua minoritaria que busca espacio, que expone estrategia política.

El autor, visto desde este ángulo, es una medida de la pertenencia a una lengua, dialecto o grupo. Este sentido es muy similar a la noción de autor en la antigüedad, pues aquel que comunica desde un reconocimiento de su legado minoritario, haciendo uso de todos esos giros de recomposición del grupo, se convierte en filtro, en representante, ya que su hacer es colectivo, su movimiento es político, es decir, comunitario. D eleuzey Guattari (1975) manifiestan con elocuencia el siguiente comentario respecto de la literatura menor:

\footnotetext{
${ }_{12}$ Es posible que esta interpretación de $D$ errida, que relaciona sus reflexiones con el concepto autor, sea producto, justamente, de un trazo, de una evocación no totalmente inconsciente ni totalmente consciente, que sea producto del vacío y la redundancia. Por otro lado, una partede la reflexión deestos críticos (Baitín, Barthes, D eleuze, D errida, Foucault y G uattari) puede ser entendida desde la teoría de la recepción, en el sentido de que la actividad autorial es una producción dela apropiación, su mensajey texto es producto dela asimilación, adaptación o rechazo. La relación entre la propuesta, se puede llamar, francesa y la teoría de la recepción, con mayor desarrollo en críticos alemanes, requeriría mayor profundización, que no es el caso detallar aquí.
} 
... N o hay sujeto, sólo hay dispositivos colectivos de enunciación; y la literatura expresa estos dispositivos en condiciones en que no existen en el exterior, donde existen sólo en tanto potencias diabólicas del futuro o como fuerzas revolucionarias por construirse... (31)

El acento puesto aquí en el aspecto político de la expresión es producto de la insistencia en denunciar que cualquier lenguaje, o su uso, implica siempre una desterritorialización de la boca, de la lengua y de los dientes (33), es un golpe continuo de disyunción entre contenido y expresión. En esto, al autor no le queda más que reconocer que es atravesado por un disparo ancestral, que es un mecanismo por el cual selibera una materia viva expresiva quehabla por sí misma (35), en donde el sentido colectivo borra al autor en tanto individualidad. EI autor es usado por, sino se mal interpreta a D eleuzey G uattari, el grito colectivo de lo menor, de la lengua vernácula, no estatal, y es punta de lanza de la procla ma de reterritorialización.

Esa voz autor, usada por un conjunto como referencia, es hablada por los mecanismos colectivos de enunciación. En ellos, se reemplaza - o desplaza- la imagen del individuo-autor por una imagen de las condiciones del discurso.

Sobre este punto, y desde una perspectiva lingüística, Bajtín (1985) nos recuerda que

los enunciados y sus tipos, es decir, los géneros discursivos, son correas de transmisión entre la historia de la sociedad y la historia de la lengua. $\mathrm{N}$ i un sólo fenómeno nuevo (fonético, léxico, de gramática) puede ser incluido en el sistema de la lengua sin pasar la larga y compleja vía de la prueba de elaboración genérica (254).

Esta imposibilidad general de saltarse a la historia - de la lengua- y, por lo tanto, la supeditación del autor a las fronteras de lo decible, es un señalamiento de que la creatividad y la individualidad serían una ilusión, de que es un simple golpe a la mesa, metafísico y arrogante del egocentrismo.

6. El desencantamiento con la noción de autor tiene aun más aristas. Bourdieu (1983) se ha encargado de sacar a flote el papel del autor como mero medio productor y reproductor de los bienes simbólicos de las esferas de poder, constreñido por las reglas del artedecada dominio artístico, intelectual o comercial. El autor es un catalizador de las expresiones sociales, construido por ellas, y que circulan con independencia deél. El autor creever en el espejo de su escritura su rostro en palabras.

Para desenmascarar esta impostura, Bourdieu (1983) reubica la categoría autor en las condiciones materiales y discursivas de su producción. El autor, 
bajo estas coordenadas, sólo utiliza los códigos apropiados de posición de la esfera a la que pertenece. En las esferas hay complejas negociaciones que se mueven al ritmo del poder ideológico. El actuar del autor sólo se coordina con la esfera o campo de poder a través del habitus, esto es:

... sistema de las disposiciones socialmente constituidas que, en cuanto estructuras estructuradas y estructurantes, son el principio generador y unificador del conjunto delas prácticas y de las ideologías características deun grupo de agentes (22).

En esta estructuración el autor es un elemento más de los bienes-de librosque senegocian en el mercado, su función es reproducirlo para reproducirse en él, para seguir existiendo; no hay, nuevamente, ni originalidad sobresaliente, ni ego superior, sólo se reaniman los buenos modales literarios. El cogito individual en Bourdieu es reemplazado por el cogito sociológico en la comprensión del autor. Uno de los aspectos centrales lo dispone Bourdieu a partir de una pregunta:

... Entonces la pregunta no será más: "¿D e qué manera tal escritor ha llegado a ser lo que es?", sino: ¿C uáles debían ser, desde el punto de vista del habitus socialmente constituido, las diversas categorías de artistas y escritores en una época dada y en una sociedad dada, para poder ocupar las posiciones pre dispuestas para ellos por un estado del campo intelectual, y para poder adoptar, en consecuencia, las tomas de posición estéticas o ideológicas ligadas objetivamente a las posiciones ocupadas? (21).

7. En el mismo sentido trabaja Jameson (1985) al exponer que la literatura, como cualquier otra manifestación artística, está determinada por los modos de producción, es decir, por las bases materiales que una sociedad crea para transmitir lo que tiene valor, de intercambio en este caso. El autor y su texto, en Jameson, vendrían a ser un vaso comunicante entre su referencia histórica inmediata y el subtexto histórico o ideológico que anima la reconstrucción. En términos específicos, Jameson recuerda que el autor, y por extensión el texto, está supeditado a la ideología de la forma, esto es, a la persistencia formal de las estructuras de alineación de la pugna presente-pasado, en que una clase hegemónica intenta imponer, vía los sistemas sígnicos específicos de ella, el contenido de la forma y la distribución de la misma.

A diferencia del concepto de habitus de Bourdieu, Jameson utiliza el deideologema, aquellas unidadesmínimas quese intercalan en, y dan vida a, las ideologías, pues son los materiales narrativos de las mismas:

El ideologema es una formación anfibia cuya característica estructural esencial puede ser descrita como una posibilidad de manifestarse ora como una 
pseudoidea - un sistema conceptual o de creencias, un valor abstracto, una opinión o un prejuicio-, ora como una protonarración, una especie de fantasíaúltima de clase sobre "Ios personajes colectivos" que son las clases en oposición (197).

El alcance real del autor para Jameson está en relación de éste con su posibilidad deuso del signo marcado por la protonarración del ideologema, producto del trasvasije de la cultura, o mejor, de la clase a la que pertenece, a su memoria arcaica, en función de su pertenencia al grupo. El autor está en continuo movimiento pendular cuyo viento son los ideologemas y cuya temperatura es la pugna constantede clases. El autor, en tanto función y responsabilidad colectiva, no tendría otra salida que cumplir su rol asignado.

8. Una posición algo similar a la deJameson tieneW hite (1987), a propósito de la función específica del historiador. Para W hite el historiador, en tanto autor, no puede escapar a la moralización narrativa, a la sujeción histórico existencial de una moral - colectiva sin duda- que ordena el historiar. En la función quele cabe al autor de historia, White expone:

... Sugiero que la exigencia de cierre en el relato histórico es una demanda de significación moral, una demanda de valorar las secuencias de acontecimientos reales en cuanto a su significación como elementos de un drama moral (35).

En esta exigencia, no obstante, no sólo se encuentra el categórico epocal, sino también la autoridad moral del narrador, lo que es una apertura hacia el autor individual - aunque no coincida con la categoría narrador- en tanto responsable de un decir. Esta apertura hacia la esfera de lo individual sólo se debe entender como una función moral, con carácter de obligatoriedad, de contar la época.

9. ¿D esde las descripciones quedevelan al autor como función discursiva, epocal y colectiva, es posible reconocer a alguien responsable de un cambio de dirección, cuyo talento o genio lo convierta en una especie de catalizador sobresaliente?

A esta pregunta Foucault (1984) contesta que sí, que es posible y necesario reconocer a autores en tanto individuos, pero que esta individualidad es dada en discurso. Se trata de los autores instauradores de discursividad que, como M arx 
o Freud, no sólo hicieron posible un cierto número de analogías, sino que hicieron posible (también) un cierto número de diferencias (68); los giros en cuestión que provocan estos autores no muestran una novedad, sino que muestran una lectura en diferencia, dada una experiencia colectiva, muchas veces, de la minoría.

Estos autores son parte del mecanismo de fundación de cientificidad, en el sentido de que la propia maquinaria de la ciencia necesita estos casos, aislados, de reorientación, y que auguran las transformaciones ulteriores. D esde esta posición, no es difícil ver en la ciencia el trabajo efectivo de los relatos y sus mecanismos discursivos de reproducción.

10. La función autor no es sólo sino una de las posibilidades de la función sujeto, aquella que nos constituyeen diferentesespacios, respecto de los disímiles requerimientos que, experimentados con mayor placer o dolor, nos abren las posibilidades de tomar distintas posiciones en comunidad.

La función del autor no radicaría en la originalidad, autonomía o inventiva, sino, en realidad, en la responsabilidad colectiva.

Con la problematización de la función del autor la subjetividad hoy, en suma, se hace más patente en términos de riesgo, experimento, diálogo, con otros, en otros ${ }^{13}$.

Q uela subjetividad sea un continuo de diálogo, no obstante, no es producto deun descubrimiento de una pretendida época posmoderna, sino que, en tanto condición reflexiva de lo contemporáneo, lo que se denomina posmodernidad seha encargado de recuperar el legado olvidado de al gunos antiguos o humanistas que, como por ejemplo M ontaigne en estosúltimos, sufrieron una derrota a manos tanto del dogmatismo religioso como filosófico; pero aun más, quizá la reflexión actual en torno al autor sólo sea una manifestación de la memoria, del eterno retorno a nuestra función para el conjunto.

${ }^{13}$ Vattimo (1992), sobre el estado actual de la vida colectiva e individual, en especial sobre la subjetividad, ha expuesto lo siguiente: “... el mundo en el que $D$ ios ha muerto porque la organización social del trabajo ha hecho superfluo el apoyo 'excesivo' que él representaba, es también el mundo en que la realidad se aligera, en el que se hace posible 'soñar sabiendo que se sueña', en el cual, en suma, la vida puede desenvolverse dentro de un horizonte menos dogmático, menos violento también, y más explícitamente dialógico, experimental, arriesgado...". En estas palabras, que son reflejo de una sensibilidad conocida pero actualizada, D ios muere como creador, como autor; no obstante, aun es un poco arriesgado, socialmente hablando, distinguirlo como una función del discurso. 


\section{BIBLIO GRAFIA}

Bajtín, M ijail. 1985. Estética de la creación verbal. M éxico: Siglo XXI.

Barthes, Roland. 1981. Crítica y verdad. M éxico: Siglo XXI.

- - - - - . 1983. El grado cero de la escritura. Buenos Aires: Siglo XXI.

Bourdieu, Pierre. 1983. C ampo del poder y campo intelectual. Buenos Aires: Folios.

Burke, Peter. 1996. Hablar y callar. Funciones sociales del lenguaje a través de la historia. Barcelona: Gedisa.

- - - . 1998. El Renacimiento europeo. Barcelona: Crítica

- - - - 2002. H istoria social del conodimiento. D eGutenberga D iderot. Barcelona: Paidós.

Cohen, Elizabeth S. \& Cohen, Thomas. 1993. Words and D eeds in Renai ssance Rome. Toronto: University of Toronto Press.

Cox, Virginia. 1992. The Renaissance dialogue: Literary D ialogue in its Social and Political Contexts. N ew York: Cambridge U niversity Press.

D eleuze, G illes \& Guattari, Félix. 1975. Kafka. Por una literatura menor. M éxico: Era.

D errida, Jacques, et al. 1971. "La différance". Tel Q uel. Teoría del conjunto. Barcelona: Seix Barral. 49-79.

Foucault, M ichel. 1984. " $Q$ ué es un autor?". Dialéctica, año IX, N 16: 51-82.

- - - - - .1987. El orden del discurso. Barcelona: Tusquets.

-------.1988 . Las palabras y las cosas. M éxico: Siglo XXI.

- - - - - . 1995. El lenguaje y las instituciones filosóficas. Barcelona: Paidós.

Frazer, James $G$ eorge. 1998. La rama dorada. M agia y religión. M éxico: Fondo de Cultura Económica.

Geertz, Clifford. 1988. Works and lives. The Anthropologist as Author. Stanford: Stanford University Press.

- - - - - . 1991. "Géneros confusos. La refiguración del pensamiento social". El surgimiento de la antropología posmoderna, G eertz, C. et al. M éxico: G edisa. 63-77.

I báñez, Jesús. 1991. El regreso del sujeto. La investi gación social de segundo orden. Santiago: Estudios Amerinda.

Ingold, Tim. 1991. Evolución y vida social. M éxico: Grijalbo.

Jameson, Fredric. 1985. "Sobrela interpretación: Ia literatura como acto socialmente simbólico". Criterios N os 13-20, I: 185- 210.

- - - - - 1991. Posmodernismo o la lógi ca cultural del capitalismo avanzado. Buenos Aires: Paidós.

Luhmann, N iklas. 1993. Teoría de la sociedad. M éxico: Universidad Iberoamericana

Lyotard, Jean. 1993. La condición posmoderna. Buenos Aires: Planeta-Agostini.

M arías, Fernando. 1989. El largo siglo XVI: los usos artísticos del Renacimiento español. $M$ adrid: Crítica.

M ontaigne, M ichel de. 1987. Escritos III. M adrid: Cátedra.

M ukarovsky, Jan. 1978. Escritos de estética y semiótica. Barcelona: Gustavo Gili.

O ng, Walter. 1997. 0 ralidad, escritura. Tecnologías de la palabra. M éxico: Fondo de Cultura Económica.

Pendás, Benigno. 1988. Jeremy Bentham: Política y derecho en los orígenes del Estado constitucional. M adrid: Centro de Estudios Constitucionales.

Ricoeur, Paul. 1999. Teoría de la interpretación. D iscurso y excedente de sentido. M éxico: Siglo XXI. 
Santibáñez, Cristián. 2002. Introducción a teorías de la argumentación. Ejemplosy análisis. Concepción: Cosmigonon.

Sokal, A. \& Bricmont, J. 1999. Imposturas intelectuales Barcelona: Paidós.

Toulmin, Stephen. 1972. Human Understanding. O xford: O xford University Press

- - - - - . 2001. Cosmópolis. El trasfondo dela modernidad. Barcelona: Península. Vattimo, Gianni. 1992. Etica de la interpretación. Buenos Aires: Paidós.

Weiss, Roberto. 1969. The Renaissance D iscovery of Classical Antiquity. 0 xford: 0 xford University Press.

White, $\mathrm{H}$ ayden. 1987. The Content of the Form. $\mathrm{N}$ arrative Discourse and Historical Representation. London: The John H opkins U niversity Press. 